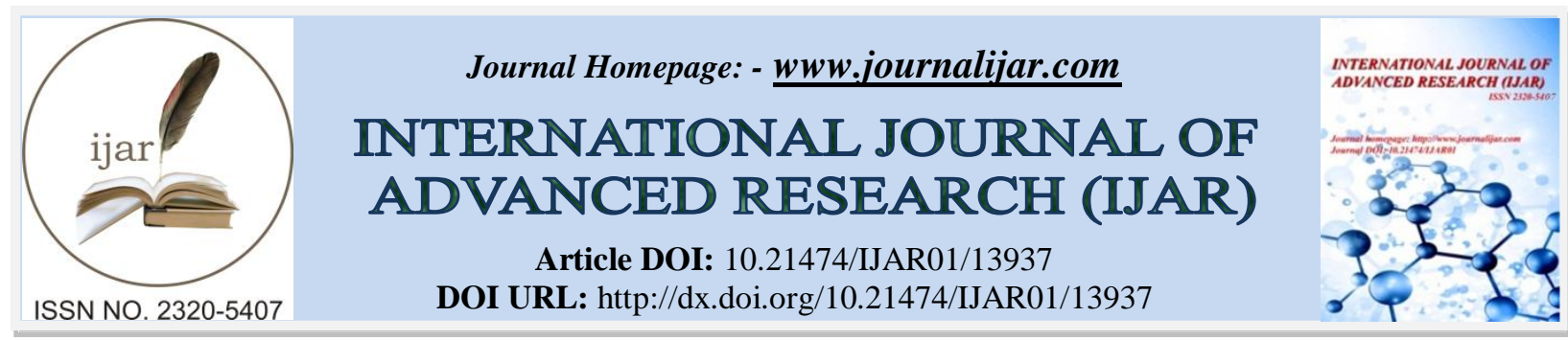

RESEARCH ARTICLE

\title{
CRITERIA FOR SELECTING SPECIAL HEALTH CARE NEEDS PATIENTS FOR GENERAL ANESTHESIA IN DENTAL TREATMENT: A SYSTEMATIC REVIEW
}

\author{
Nourah Al-Lwemi ${ }^{1}$, Nuha Al-Shalabi ${ }^{1}$, Noor Al-Basheeti ${ }^{1}$, Hafsa Yasser $^{1}$ and Shahzeb Ansari ${ }^{2}$ \\ 1. Senior Dental Student, Riyadh Elm University, College of Dentistry. \\ 2. Faculty Preventive Dentistry, Riyadh Elm University, KSA.
}

\section{Manuscript Info}

…......................

Manuscript History

Received: 15 October 2021

Final Accepted: 18 November 2021

Published: December 2021

Key words:-

"Special Needs", "Special Health Care

Needs", and "General Anesthesia"

\section{Abstract}

Objective:This systematic review aimed to investigate the available evidence on how to decide whether your special health care needs patient needs GA for dental treatments or not.

Materials and methods: A systematic search was conducted in four electronic databases PubMed, Google Scholar, ResearchGate and SDL. The search was restricted to articles published between 2005 and 2020. Publications reporting on the special health care needs patient's dental treatment were included. The papers were analyzed regarding title and abstract contents to eliminate the ones that were out of context and not relevant to the review.

Results:The search strategy resulted in 99 unique and potentially relevant articles. In total, 6 publications which include 5 retrospective articles and one cross-sectional study were selected.

Conclusions:The main standards for selecting patients for hospitalized dental treatments include a full analysis of SNP including their medical history, behavior and emotional factors, oral health status, allergies, social and non-clinical factors, and caregivers' factors. It is important for general dentists and families of these patients to be acquainted with the procedure, its need, and its contraindications.

Copy Right, IJAR, 2021,. All rights reserved.

\section{Introduction:-}

Disabilities affect many people today. Prevalence varies between different countries and cultures, but it is realistic to assume that up to twenty percent of all children and adolescents may be affected by a disability or a chronic health condition (Merrick and Carmeli, 2003; Bethell et al., 2008). Further, the number of individuals with disabilities is increasing owing to developments in medical health technology, diagnostic tools, and an increase in the number of medical treatment options (Wright and Kupietzky, 2014).

The American Academy of Pediatric Dentistry (AAPD) recognizes that providing both primary and comprehensive preventive and therapeutic oral health care to individuals with special health care needs (SHCN) is an integral part of the specialty of pediatric dentistry. Recently, special health care needs dentistry has just got recognized as a separate branch of dentistry. Special needs dentistry is a recognized dental specialty in Australia and New Zealand, but in all other countries around the world it is still a part of the pedodontic specialty (Lim and Borromeo, 2017).

Corresponding Author:- Nourah Al-Lwemi

Address:- Senior Dental Student, Riyadh Elm University, College of Dentistry. 
As defined by the AAPD, special health care needs are "any physical, developmental, mental, sensory, behavioral, cognitive, emotional impairment or limiting condition that requires medical management, health care intervention, and/or use of specialized services or programs" (American Academy of Pediatric Dentistry, 2020:19).

Special health care needs patients with complex cases may have a higher chance of oral diseases due to decreased oral health and ability to maintain oral hygiene (Norderyd et al., 2016). According to IBGE and the Ministry of health, $6.7 \%$ of the population may require special needs dental treatment. Among those, $5 \%$ may need hospital treatment under sedation and/or general anesthesia-GA- (Santos et al., 2015). The clinical care of patients with special health care needs should be based on risk assessment, where the general health status is related to the level of collaboration in dental treatment and dental needs. Thereafter, behavior management techniques must be used first, but in the event of failure, GA is an alternative for patients who reject all types of behavior management. Dental Management of Special Needs Patients: A Literature Review (Munhoz, 2018). GA can be in a lot of situations the best choice of treatment for many special health care needs patients who cannot be treated in any other way (de Nova et al., 2008). As explained by ADA "general anesthesia is a drug-induced loss of consciousness during which patients are not arousable, even by painful stimulation. The ability to independently maintain ventilatory function is often impaired" (American Dental Association, 2016). Furthermore, GA has been determined to be a safe method of treatment with low risk of severe complications or deaths (Caputo, 2009). Dental treatment of these patients usually presents a challenge for dentists, due to the non-viable standard treatment for these patients (DMD et al., 2010).

We conclude that knowledge of how to decide whether your special health care needs patient is in need of GA or not is one of the most important decisions that a dentist has to make.

\section{Research Question}

The PICO model was used to write the research question, which includes patient, intervention, comparison, and outcome. Is every special health care needs patient considered a candidate for dental treatment under general anesthesia?

\section{Aim of the study}

To how to decide whether your special health care needs patient is in need of GA or not.

\section{Justifications and target audience}

The knowledge of how to decide whether your special health care needs patient is in need of GA or not is one of the most important decisions that a dentist has to make. The target audience of this systematic review includes general dental practitioners.

\section{Methodology:-}

A systematic literature review from 2005 to 2020 was performed using such databases as PubMed, Google Scholar, SDL, and ResearchGate. We have searched for all relevant publications where the researchers talked about the special health care needs treatment modalities. The key words used were "Special needs", "Special health care needs", and "General anesthesia". Our topic was never done as a systematic review before, but it was done as a clinical trial in January 2008. Our research will be the first systematic literature review on this topic. The following search in databases resulted in a total of 94 citations found. After adjusting for duplicates, 64 publications remained. The abstracts of these articles have been reviewed, after which 55 studies were discarded because they did not meet the inclusion criteria.

\section{Inclusion criteria}

The following criteria were considered essential for the inclusion into the systematic review:(1) Case control, survey, experimental, randomized, cross-sectional, cohort and observational studies. (2) Published between 2005 and 2020. (3) English language of publication. (4) All Special health careneeds. (5) Age range(between1to 60 years).

\section{Exclusion criteria:}

The exclusion criteria were as follows: (1) Lab trials, meta-analysis, systematic review, case report and case series. (2) Out of the specified time range. (3) Language other than English. (4) Healthy patients. (5) Age above 60.

\section{Results:-}

A total of 99 articles were initially retrieved from the four databases (PubMed, SDL, ResearchGate, and Google Scholar). Following a manual search. After searching the databases and eliminating the duplicate articles, 66 papers were screened by title and abstract against the inclusion criteria. After applying the inclusion and exclusion criteria, 6 studies have met all pre 
set criteria for our systematic review. All of them were published between 2005 and 2020.The PRISMA flow diagram representing the selection process is given in Figure 1.

\section{Study characteristics}

Among the 6 eligible papers, five reported as retrospective studies, and one as a cross-sectional study.

\section{Results of individual studies}

A backdated retrospective study conducted by (Tsai et al. in 2006), aimed to determine the characteristics of the comprehensive dental treatments that were performed on children with rampant caries under general anesthesia, in addition to identifying the differences between the dental treatment provided under general anesthesia for children with and without a chronicillness and/or disability. Data was collected from children who received dental care under general anesthesia at Kaohsiung Chang-Gung Memorial Hospital over a 1-year period.Sample size was 184 patients (aged under 18). The patients were divided into two groups (I, II) according to their health status (special needs, relatively normal) respectively.Twosamples, t-tests, and Chi-square tests were respectively used to compare numerical and categorical variables between the two groups.Different dental treatments were noted when the two groups were compared. Significantly greater numbers ofstainless-steel crown build-ups $(p=0.028)$ and pulpal treatments $(p=0.003)$ were found among group II patients. There were no significant differences between the two groups in restorations $(p=0.934)$; however, group I had a significantly higher $(p=0.006)$ number of extractions. It was inferred that the need for dental treatment under general anesthesiaexists for disabled or chronically ill patients in every age group.

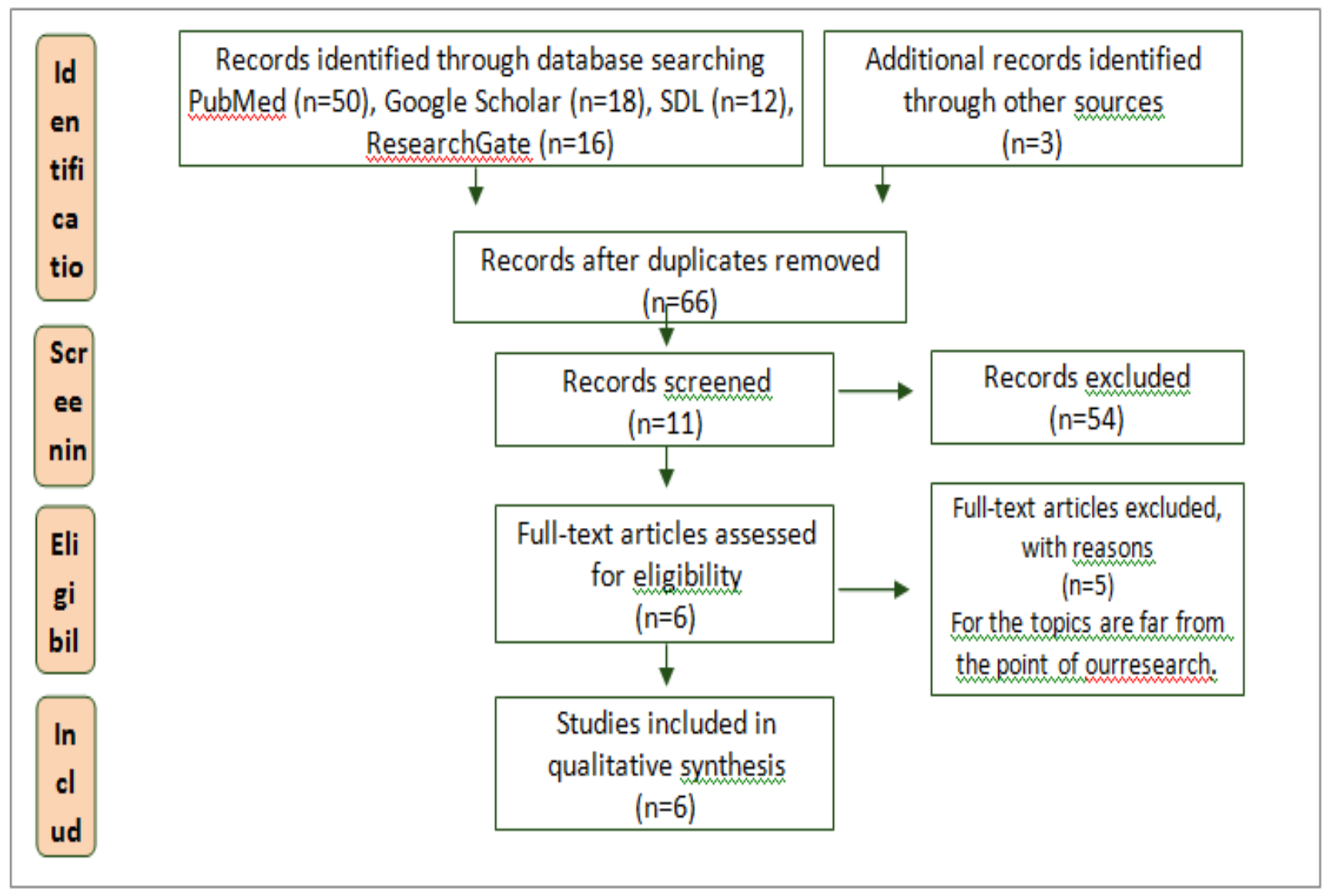

Figure 1:- PRISMA flow chart.

In 2007, other researchers, (de Nova et al.) had conducted a cross sectional study aimed to studythe criteria that help to select children with special needs for dental treatment under general anesthesia. The record was collected of patients receiving dental treatment at the time on the UCM Course for Experts on clinical dental care for disabled children. Sample size was of 30 patients (aged under 18) were referred to the Disabled Children's Oral Health Unit (DCOHU) within Primary Health Care Area 2 of the Madrid Health Service (SERMAS) for treatment and/or completion of dental treatment under general anesthesia. All the patients had a clinical history covering, among others, the following three sections: (A) Evaluation 
of general health (B) Evaluation of oral health (C) Evaluation of behaviouranesthesia. In most of the children (22 children), it was possible to carry out a complete dental diagnosis. With regard to medical diagnoses, the most frequent pathology was cerebral palsy ( 8 children). Regarding oral health, most of the children received restorative treatment in all 4 quadrants $(26$ children). On the basis of scales for behavioural evaluation and movement, most of the children (17 children) clearly showed a negative behaviour; with movements that interrupted or hindered examination.

Simultaneously in the same year, (in 2007 Messieha et al.) had conducted another retrospective study to identify the special elements of the dental elements with special needs that are seen as contributors to the anesthetic risks. What they assessed in the study was the level of safety of general anesthesia for dental treatment of patients with special needs according to the classifications, procedures, and other contributors of the American Society of Anesthesiology Physical Status (ASAPS). The number of the participants in this study was 363 of the aforementioned group (age mean $46.93 \pm 16.835$ years), 180 in male and 183 in female. Data was collected from the population of the University of Illinois at Chicago. The clinical records that the participants, who were admitted to the University for comprehensive dental rehabilitation under general anesthesia within the period of 5 years, were assessed and reviewed by one of the researchers in this study. The data included every single detail in the records, such as age, gender, ASAPS classification, duration of anesthesia, and any intraoperative or postoperative morbidity. Clinical records, which their data was included in the study, were 425 , the 62 left were execludedfrom the data analysis stage as they did not meet the requirements of the Anesthesiology Physical Status Classification (ASAPS). The investigators noticed two morbidities in the records; one of them was because of the maximal mouth opening, and the surgeon was unable to control over his airway during the hospital admission by performing a tracheostomy as a more extreme measure. The other one that was noticed wasbecause of the venous access of the patient and lack of cooperation. The concentration of hemoglobin was very difficult to be obtained pre the date of the procedure. By and large, it was found that there is safety in the dental rehabilitation of special needs patients under general anesthesia.

Another backdated retrospective study conducted in 2012. Abdulhameed, had conducted a retrospective study to see the features and the performed treatment modalities under general anesthesia in pediatric dental patients at Baghdad Private Hospitals between 1990 and 2011. Further, the researcher compared the various treatment patterns in normal children and children with special health care needs. The method that was taken place was as follow: the participants were broken down into two groups: group A (disabled group) involved the children with special health care needs who had at least one type of mental or physical disability, group B (healthy group) involved the fully healthy participants who have neither mental nor physical disabilities, the age ranged between 1 and 18 years old. One pediatric dentist had performed all dental treatments, the dental treatment that was performed under general anesthesia in the hospital environment provides the particular groups of patients, such as very young or disabled children, with great effectiveness. In their study and during a single operation, the groups that received treatment for 13.5 teeth on average during a single operation were 105 young healthy children (mean age 3.7 years). The mean number of the treated teeth between the two groups were almost equal as there were no major differences between them. However, there was a significantly greater mean total number of the extracted teeth in group A patients $(\mathrm{p}<0.001)$. Moreover, there were more stainless-steel crown reconstructions $(\mathrm{p}<0.05)$ and pulp therapies $(\mathrm{p}<$ $0.001)$ performed in group B patients. In group A, there were no significant differences in the total number of extracted teeth between the 1-3 years old patients and the 3-6-year-old patients $(\mathrm{p}=0.99)$.

In 2014, (Chia-Yu et al.) had also conducted a retrospective study of the oral health status of children with special health care needs (CSHCN) who received their first comprehensive dental treatment at Taipei Veterans General Hospital (Taipei, Taiwan). The study aimed to analyze whether different patterns of dental treatment exist across disability and age groups. The total number of participants was 96 (62 boys and 34 girls). They collected data from each participant according to such criteria (age, sex, medical diagnosis and severity of disability, oral health status, and types and numbers of treatments). Types and severity of disability were recorded according to the patient's National Disability Certificate and medical history records. They compiled and calculated the frequency and distribution of patients' general characteristics. They dichotomized the patients into two groups according to age (young: 2-6 years vs. older: $>6$ years), then they assessed the correlation between the age groups and oral health status by using the independent t-test and the Chi-square test. Finally, they demonstrated the relationship between the type and severity of disabilities and oral health status by using a one-way analysis of variance (ANOVA) and a Chi-square test. The deft/DMFT index was significantly higher in the younger age group (2-6 years; $13.8 \pm$ 4.3) compared to the older group (> 6 years; $10.5 \pm 5.3 ; \mathrm{p}<0.001$ ). The mean number of total treated teeth was $14.2 \pm 3.8$, and no differences existed among disability groups $(\mathrm{p}=0.528)$ and age groups $(\mathrm{p}=0.992)$. For the treatment modality, the number of pulp therapies with crown restoration was higher in the younger age group than in the older group. They observed significantly more malocclusion of full permanent dentition in the older age group (91\%) than in the younger group (35\%; $\mathrm{p}$ $<0.001)$. The prevalence of caries and the DMFT index rises every year after the age of 12 years. The malocclusion conditions they observed in the patients were mostly related to space problems resulting from premature loss of deciduous 
teeth at an early age, such as ectopic eruption or impacted permanent canines and premolars and dentition crowding. This indicates that early intervention of oral health care facilitates full mouth rehabilitation in young children. In contrast to our hypothesis that children who were severely disabled or had certain types of disability such as autism, Down syndrome, and multi-disabilities would have more unmet dental needs, we observed no significant difference in the deft/DMFT index and dental treatment modalities regarding disability type and severity. In conclusion, unmet dental needs and caries experience indices remain high, regardless of disability types and severity in Taiwan. They concluded that early dental intervention and preventive approaches for oral care are mandatory for CSHCN.

In 2019, (Özükoç et al.) designed a retrospective study. The purpose of this study was to determine the characteristics of children treated under GA according to age, gender and medical condition, investigate different indications for the dental treatment in children, and to assess the mean number of different dental procedures performed under GA in a single dental care unit one year. Data was collected from patient's rehabilitation under general anesthesia over a period of one year (February-2018 to January-2019). The information collected from the records included age, gender, general health status, indications for general anesthesia, type of procedure, attendance for review appointment and treatment including the number of primary and permanent teeth extracted and restored. Sample size was 107 patients (64 male and 43 female). All participants received dental treatment under general anesthesia at a private dental clinic in Istanbul, Turkey. ANOVA test was used to compare the means of multiple variables. An Independent-Samples T-test was used to compare the means of two variables, while the Chi-Square test was used when proportions were compared. The level of statistical significance was chosen at $\mathrm{p}<0.05$. The evaluation of the indications for GA revealed that the most common indication was behavior management problem, which was observed in $52(48.59 \%)$ patients, and it was mostly in the 2-5 year age group (35.51\%). The rate of children with disabilities was determined as $29.90 \%$, and it was observed that they were mostly in the 10-12 age group $(16.82 \%)$. It was determined that the rates of children assigned for oral surgical procedure were equal (1.87\%) in the 69 and 10-12 age groups. The evaluation of the correlation between the existing procedures and GA indications revealed that the rate of fillings in primary teeth was higher among the children with behavior management problems (54.47\%), whereas the rate of primary teeth pulpotomy $(56 \%)$ and endodontic treatment in primary teeth $(56.25 \%)$ was higher among the children with severe tooth decay. The rate of endodontic treatment $(78.57 \%)$ and the rate of permanent teeth extraction $(68.88 \%)$ were higher in children with disabilities. At the end of this study, they conclude that GA can be used in pediatric patients with mental or physical disabilities as well as in healthy children with poor cooperation or those who cannot be persuaded through cognitive therapy. The most frequent mutual causes for GA are the absence of cooperation or behavior management problems in children, mental and physical disabilities, and the requirement for comprehensive dental treatment due to the severe tooth decay. GA is frequently preferred for providing high standard dental treatment for patients with mental and physical disabilities. Finally, they found out that $32(29.9 \%)$ patients required special health care, whereas 75 $(70.1 \%)$ patients consisted of healthy children, which was consistent with the other studies.

\section{Quality assessment}

\section{Risk of bias}

The methodological quality of the studies was assessed using the National Heart, Lung, and Blood Institute (NHLBI) quality assessment tool. According to the risk of bias classification, the six studies overall were considered as good quality, and low risk of bias(Table 1).

\section{Discussion:-}

In our study, a systematic review of the available evidence on criteria of selecting special health care needs patients for GA was performed. The main concept of our systematic review is to search in depth about SHCN patients in the dentistry field and how to consider their differences from healthy patients. We found a lot of definitions for those patients, but it is still very difficult to contain all possible conditions in one sentence. Due to that reason, we specified our research on the criteria that form the main difficulties any patient, with any kind of disability, can face.SHCN patients can face mental, physical, behavioral, etc... problems, but still SHCN can enhance someone's life in the sameway it can cause challenges. Someone with SHCNmay need help with vital activities ranging from movementor communication to making important decisions and taking care of themselves, which makes sometimes even the smallest dental treatments difficult. which makes sometimes even the smallest dental treatments difficult.

Table 1:- Quality Assessment Tool for ObservationalCohort and Cross-SectionalStudies.

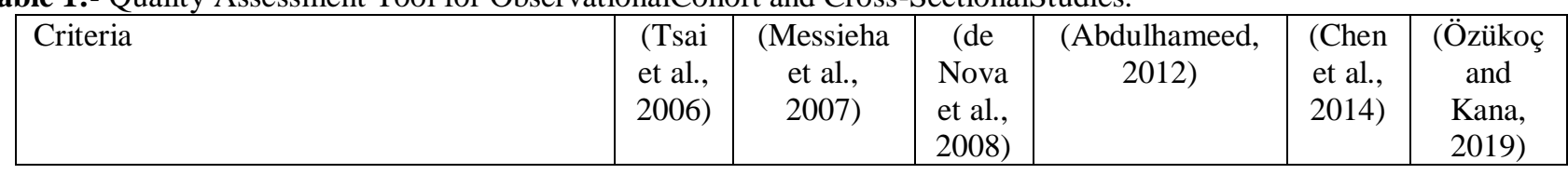




\begin{tabular}{|c|c|c|c|c|c|c|}
\hline $\begin{array}{l}\text { 1. Was the research question or objective } \\
\text { in this paper clearly stated? }\end{array}$ & YES & YES & YES & YES & YES & YES \\
\hline $\begin{array}{l}\text { 2. Was the study population clearly } \\
\text { specified and defined? }\end{array}$ & YES & YES & YES & YES & YES & YES \\
\hline $\begin{array}{l}\text { 3. Was the participation rate of eligible } \\
\text { persons at least } 50 \% \text { ? }\end{array}$ & YES & YES & YES & YES & YES & YES \\
\hline $\begin{array}{l}\text { 4. Were all the subjects selected or } \\
\text { recruited from the same or similar } \\
\text { populations (including the same time } \\
\text { period)? Were inclusion and exclusion } \\
\text { criteria for being in the study prespecified } \\
\text { and applied uniformly to all participants? }\end{array}$ & YES & YES & YES & YES & YES & YES \\
\hline $\begin{array}{l}\text { 5. Was a sample size justification, power } \\
\text { description, or variance and effect } \\
\text { estimates provided? }\end{array}$ & YES & YES & YES & YES & YES & YES \\
\hline $\begin{array}{l}\text { 6. For the analyses in this paper, were the } \\
\text { exposure(s) of interest measured prior to } \\
\text { the outcome(s) being measured? }\end{array}$ & YES & YES & YES & YES & YES & YES \\
\hline $\begin{array}{l}\text { 7. Was the timeframe sufficient so that one } \\
\text { could reasonably expect to see an } \\
\text { association between exposure and outcome } \\
\text { if it existed? }\end{array}$ & YES & YES & NA & YES & YES & $\mathrm{NO}$ \\
\hline $\begin{array}{l}\text { 8. For exposures that can vary in amount } \\
\text { or level, did the study examine different } \\
\text { levels of the exposure as related to the } \\
\text { outcome (e.g., categories of exposure, or } \\
\text { exposure measured as continuous } \\
\text { variable)? }\end{array}$ & NA & NA & NA & NA & NA & NA \\
\hline $\begin{array}{l}\text { 9. Were the exposure measures } \\
\text { (independent variables) clearly defined, } \\
\text { valid, reliable, and implemented } \\
\text { consistently across all study participants? }\end{array}$ & YES & YES & YES & YES & YES & YES \\
\hline $\begin{array}{l}\text { 10. Was the exposure(s) assessed more } \\
\text { than once over time? }\end{array}$ & NR & NR & NR & NR & NR & NR \\
\hline $\begin{array}{l}\text { 11. Were the outcome measures } \\
\text { (dependent variables) clearly defined, } \\
\text { valid, reliable, and implemented } \\
\text { consistently across all study participants? }\end{array}$ & YES & YES & YES & YES & YES & YES \\
\hline $\begin{array}{l}\text { 12. Were the outcome assessors blinded to } \\
\text { the exposure status of participants? }\end{array}$ & $\mathrm{NO}$ & $\mathrm{NO}$ & $\mathrm{NO}$ & NO & NO & NO \\
\hline $\begin{array}{l}\text { 13. Was loss to follow-up after baseline } \\
20 \% \text { or less? }\end{array}$ & NA & NA & NA & NA & NA & NA \\
\hline $\begin{array}{l}\text { 14. Were key potential confounding } \\
\text { variables measured and adjusted } \\
\text { statistically for their impact on the } \\
\text { relationship between exposure(s) and } \\
\text { outcome(s)? }\end{array}$ & YES & YES & YES & YES & YES & YES \\
\hline
\end{tabular}

*NA, not applicable; NR, not reported.

There are many ways to manage these conditions but one of the most controversial ways is treatment under full sedation or general anesthesia. Some of the pedodontists and researchers say general anesthesia should be the last option to consider when trying to treat SHCN patients, but this opinion is still against the saying that treatment under GA for those patients should be as early as possible to prevent further complications and more extensive options of treatment. 
In one of our selected articles, (de Nova et al., 2008) were following the concept of using the GA as the last source for treatment based on their research on this topic. On the contrary, (Chen et al., 2014) concluded that it is mandatory to start the oral care for these patients as early as possible to avoid worsening of their oral conditions. That point was also supported in the research of (Tsai et al., 2006), who recommended the referral of these patients to the hospital for treatment as early as possible to improve their health and maintain the treatment in the range of restorations and not reach the need for extractions.

Early or late, the decision in both cases should follow certain important rules when dealing with these patients. A comprehensive assessment of a patient's medical status is a standard practice when dental care is provided. No SHCN patient should be considered fit for selection under any criteria for treatment under GA before considering the medical condition, medications, preanesthetic, and surgical evaluations for these patients. (Messieha et al., 2007) in their study stated the importance of setting up a risk versus benefit assessment for any procedures that will be done since dealing with those patients can be very unexpected and medical staff should be as prepared for it as possible. They supposed that patients who have a problem with GA treatment due to high demand for care regarding these standards, will probably not allow a comprehensive examination in the first place.

According to (Tsai et al., 2006), the indications for treatment under general anesthesia are extensive decay, behavioral management problems, a medically compromised patient, a handicapped patient, and a combination of these in every age group according to their findings in their study. These main points were also supported in (de Nova et al., 2008) article through research on this topic in various other articles. However, these reasons cannot be outlined as the only ones that justify the use of GA. Özükoç and Kanat backed up these reasons, adding extreme anxiety and fear to those behavioral reasons for those patients, and children requiring oral surgery.(Abdulhameed, 2012) found another need for referral, that was not mentioned in other researches,identified as lack of psychological or emotional maturity. In addition to the previous causes, treatment under GA is necessary for patients allergic to local anesthesia (Carson and Freeman, 2001). In one of the articles in our review, Hulland and Sigalqouted that adding forgotten reasons that usually skip the minds of dentists including non-clinical considerations and social factors in general.

Most of the researchers agreed that treatments under GA for such complex cases in all levels can ensure a higher quality treatments than anything that can be done while the patients are conscious. Better treatment, improving quality of life and easier procedures for the dentists are all benefits of going with the GA option.

(Chen et al., 2014) in their research, spoke briefly about the parents or caregiver on SHCN patients. Caregivers are a key factor in the treatment options for SHCN patients, since they are the ones responsible for caring and seeking care for these patients because usually they do not have the ability and awareness to care for themselves. (SAVANHEIMO et al., 2005) stated that recently, parents have been asking for treatment under GA, even in healthy patients due to dental fear, recurrent problems and unpleasant troublesome experiences during dental treatment. Lately, for the dentists it might be sometimes the last option, whereas it might be the first option for some caregivers.

In the final analysis, the concept of "dental home" must be promoted, especially for SHCN patients, and the guidance of oral hygiene maintenance should be provided to disabled children and their guardians throughout the critical developmental stage (Chen et al., 2014). After going through the referrals for these patients, it is usually from general practitioners or the patients themselves which makes their awareness very important and setting criteria available for them is very essential.

All of these reasons clarified enough that not every SHCN patient should be referred to GA unless the analysis of all these criteria tells otherwise. Further research about this topic is still needed to cover up all the conditions and complexities of SHCN patients.

\section{Conclusion:-}

There can be no doubt that setting a standard way of selecting patients for hospitalized dental treatments is very critical. To wrap up, we can say that the main criteria include a full analysis of SNP including their medical history, behaviour and emotional factors, oral health status, allergies, social and non-clinical factors, and caregivers factors. It should always be emphasized that general dentists and families of these patients have to be acquainted with the procedure, its need, and its contraindications. 


\section{Funding}

None needed.

\section{Ethical approval}

Not applicable. This was not a research study.

\section{Patient consent}

Not required.

\section{References:-}

1. Abdulhameed, S.M., 2012. Dental Treatments during full mouth rehabilitation under General Anesthesia in Healthy and special needs pediatric dental patients in Baghdad, Iraq. Iraqi Dental Journal 34, 52-57.

2. American Academy of Pediatric Dentistry. Definition of special health care needs. The Reference Manual of Pediatric Dentistry. Chicago, Ill.: American Academy of Pediatric Dentistry; 2020:19.

3. American Dental Association, 2016.Guidelines for the use of sedation and general anesthesia by dentists.Adopted by the ADA House of Delegates.

4. Bethell, C.D., Read, D., Blumberg, S.J., Newacheck, P.W., 2008. What is the prevalence of children with special health care needs? Toward an understanding of variations in findings and methods across three national surveys. Matern Child Health J 12, 1-14.

5. Caputo, A., 2009. Providing deep sedation and general anesthesia for patients with special needs in the dental office-based setting. Special care in dentistry: official publication of the American Association of Hospital Dentists, the Academy of Dentistry for the Handicapped, and the American Society for Geriatric Dentistry 29, 26-30.

6. Carson, P., Freeman, R., 2001. Dental caries, age and anxiety: factors influencing sedation choice for children attending for emergency dental care. Community Dentistry and Oral Epidemiology 29, 30-36.

7. Chen, C.-Y., Chen, Y.-W., Tsai, T.-P., Shih, W.-Y., 2014. Oral health status of children with special health care needs receiving dental treatment under general anesthesia at the dental clinic of Taipei Veterans General Hospital in Taiwan. Journal of the Chinese Medical Association 77, 198-202.

8. de Nova, J., Gallardo, N., Sanjuán, C., Martínez, M., García, Y., Cabaleiro, E., 2008. Criteria for selecting children with special needs for dental treatment under general anaesthesia.Medicina oral, patología oral y cirugíabucal 12, E496-503.

9. DMD, S., MPH, P., DMD, C., RDH, B., MA, J., Boynes, S., Moore, P., Lewis, C., Zovko, J., Close, J., 2010. Complications associated with anesthesia administration for dental treatment in a special needs clinic. Special Care in Dentistry 30, 3-7.

10. Hulland, S., Sigal, M.J., 2000. Hospital-based dental care for persons with disabilities: a study of patient selection criteria. Special Care in Dentistry 20, 131-138.

11. Lim, M., Borromeo, G., 2017.The use of general anesthesia to facilitate dental treatment in adult patients with special needs.Journal of Dental Anesthesia and Pain Medicine 17, 91.

12. Merrick, J., Carmeli, E., 2003. A Review On The Prevalence Of Disabilities In Children. The Internet Journal of Pediatrics and Neonatology 4.

13. Messieha, Z., Ananda, R.C., Hoffman, I., Hoffman, W., 2007. Five Year Outcomes Study of Dental Rehabilitation Conducted Under General Anesthesia for Special Needs Patients. Anesthesia Progress 54, 170174 .

14. Munhoz, E., 2018. Dental Management of Special Needs Patients: A Literature Review. Global Journal of Oral Science 2, 33-45.

15. Norderyd, J., Klingberg, G., Faulks, D., Granlund, M., 2016.Specialised dental care for children with complex disabilities focusing on child'sfunctioning and need for general anaesthesia. Disability and Rehabilitation 39, 18.

16. Özükoç, C., Kanat, A., 2019. Dentistry Analysıs of Pediatric Dentistry Patients Treated Under General Anesthesia.

17. Santos, J.S., Valle, D.A., Palmier, A.C., Amaral, J.H.L. do, Abreu, M.H.N.G. de, 2015. Utilização dos serviços de atendimentoodontológicohospitalar sob sedação e/ouanestesiageralporpessoas com necessidadesespeciais no SUS-MG, Brasil. Ciênc.saúdecoletiva 20, 515-524.

18. SAVANHEIMO, N., VEHKALAHTI, M.M., PIHAKARI, A., NUMMINEN, M., 2005.Reasons for and parental satisfaction with children's dental care under general anesthesia. International Journal of Paediatric Dentistry 15, 448-454. 
19. Tsai, C.-L., Tsai, Y.-L., Lin, Yng-Tzer, Lin, Yai-Tin, 2006. A Retrospective Study of Dental Treatment under General Anesthesia of Children with or without A Chronic Illness and/or A Disability 29, 7.

20. Wright, G., Kupietzky, A., 2014. Behavior Management in Dentistry for Children, Second Edition. pp. 125129. 